See discussions, stats, and author profiles for this publication at:

https://www.researchgate.net/publication/272183798

\title{
Moral Enhancement: Do Means Matter Morally?
}

ARTICLE in NEUROETHICS · FEBRUARY 2015

Impact Factor: $1.31 \cdot$ DOI: 10.1007/s12152-015-9230-y

CITATIONS

4

2 AUTHORS:

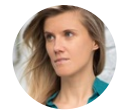

Farah Focquaert

Ghent University

30 PUBLICATIONS 139 CITATIONS

SEE PROFILE
READS
Maartje Schermer

Erasmus MC

79 PUBLICATIONS 666 CITATIONS

SEE PROFILE 


\title{
Moral Enhancement: Do Means Matter Morally?
}

\author{
Farah Focquaert • Maartje Schermer
}

Received: 17 October 2014 / Accepted: 22 January 2015 /Published online: 11 February 2015

C) Springer Science+Business Media Dordrecht 2015

\begin{abstract}
One of the reasons why moral enhancement may be controversial, is because the advantages of moral enhancement may fall upon society rather than on those who are enhanced. If directed at individuals with certain counter-moral traits it may have direct societal benefits by lowering immoral behavior and increasing public safety, but it is not directly clear if this also benefits the individual in question. In this paper, we will discuss what we consider to be moral enhancement, how different means may be used to achieve it and whether the means we employ to reach moral enhancement matter morally. Are certain means to achieve moral enhancement wrong in themselves? Are certain means to achieve moral enhancement better than others, and if so, why? More specifically, we will investigate whether the difference between direct and indirect moral enhancement matters morally. Is it the case that indirect means are morally preferable to direct means of moral enhancement and can we indeed
\end{abstract}

F. Focquaert $(\bowtie)$

Bioethics Institute Ghent, Department of Philosophy and Moral Sciences, Ghent University, Blandijnberg 2, 9000 Gent, Belgium

e-mail: farah.focquaert@UGent.be

M. Schermer

Department of Medical Ethics and Philosophy, PO Box 2040, 3000 CA Rotterdam, The Netherlands pinpoint relevant intrinsic, moral differences between both? We argue that the distinction between direct and indirect means is indeed morally relevant, but only insofar as it tracks an underlying distinction between active and passive interventions. Although passive interventions can be ethical provided specific safeguards are put in place, these interventions exhibit a greater potential to compromise autonomy and disrupt identity.

Keywords Moral enhancement - Enhancement · Bioenhancement · Biomedical enhancement - Identity . Autonomy

\section{Introduction}

An enhancement can be broadly defined as any "deliberate intervention ... which aims to improve an existing capacity that most or all human beings typically have, or to create a new capacity" [1: 23]. When these interventions are biomedical or biotechnological in nature and act directly on the body or brain, we can speak of biomedical enhancement. In this article we focus on moral enhancement, because this is a relatively new and controversial concept. Moral enhancement is more complex compared to most forms of (cognitive) enhancement, in which typically one more-or-less 
isolated trait is targeted, and attitudes towards moral enhancement appear to be more varied. ${ }^{1}$ One of the reasons it is controversial, is because the advantages of moral enhancement may fall upon society rather than on those who are enhanced. If directed at individuals with certain counter-moral traits it may have direct societal benefits by lowering immoral behavior and increasing public safety, but it is not directly clear if this also benefits the individual in question. Finally, the risk of abuse seems greater in comparison to other kinds of enhancement because of the lack of agreement on what counts as 'morally better' behavior [2].

There is currently no consensus on what moral enhancement means exactly. Several proposals have been made in the literature, expressing quite different views of what moral enhancement is or should be. Some definitions focus on moral behavior or the outcomes of behavior, others on the process of moral decision making, on human virtues, on cognitive or affective capacities et cetera [2]. The means that are suggested to reach moral enhancement may also differ substantially. For example, Persson and Savulescu [3] argue that there is an urgent need to discover biological and genetic means of moral enhancement, while others argue that many useful ways of morally enhancing individuals are already at our disposal. For instance, John Harris [4] reminds us of various attractive and effective examples of moral enhancement that are readily available, tried and tested

\footnotetext{
${ }^{1}$ A questionnaire among the general public and GPs revealed both groups are more reluctant towards the use of pharmaceuticals for enhancement purposes if used for purely egoistic reasons compared to socially related reasons [41]. Targeting morality may therefore be more acceptable compared to other types of enhancement due to inherent societal benefits if moral enhancement is successful. On the other hand, because our moral characteristics can be considered essential, deeply inherent traits of our personality and self-identity, enhancing such traits in oneself and/or others may be met with more reluctance compared to enhancing cognitive traits such as attention or memory [13, 42]. Riis and colleagues [42] found that out of 19 cognitive, emotional and social traits, people were least willing to pharmaceutically enhance the most morally significant traits included in the list (i.e., empathy and kindness). Also, many individuals favored a ban on pharmaceutical enhancements of empathy and kindness in others (40\% and $43 \%$ respectively), although 7 other traits scored similar or higher (e.g., math ability and wakefulness).
}

(e.g., moral education), but have received little attention in the moral enhancement literature.

New and emerging neuroscientific interventions that are being tested and developed to treat diseases, such as transcranial magnetic stimulation (TMS), transcranial direct current stimulation (tDCS), deep brain stimulation (DBS) or various drugs, may have the potential to be used for moral enhancement. Forms of neuromodulation - such as TMS or DBS - that work directly on the brain, can be contrasted with indirect means for moral enhancement such as education or therapy. The question we want to answer is whether this difference is morally relevant.

In this paper we will first discuss the nature of moral decision-making and behavior, which in our view involves cognitive, affective and motivational processing, and the complex interplay between these. We will discuss what we consider to be moral enhancement and how different means may be used to achieve it. Next, we will discuss whether the means we employ to reach moral enhancement matter morally. Are certain means to achieve moral enhancement wrong in themselves? Are certain means to achieve moral enhancement better than others, and if so, why? More specifically, we will investigate whether the difference between direct and indirect moral enhancement matters morally. We draw upon Neil Levy's 'parity principle': "Unless we can identify ethically relevant differences between internal and external interventions and alterations, we ought to treat them on a par." [5: 62]. Unlike for example Hank Greely, who has stated that he sees "no qualitative difference between acting directly to change a criminal's brain - through drugs, surgery, DBS, or vaccines, if proven safe and effective - and acting indirectly - through punishment, rehabilitation, cognitive therapy, parole conditions - to achieve similar ends" [6: 1134], we will argue that there is a relevant difference that warrants a different treatment of different interventions.

We will argue, however, that the morally relevant difference is not that between direct and indirect interventions per se, but between what we will call active and passive interventions. Active interventions require specific psychological and/or behavioral efforts on behalf of the 
individual to achieve the desired end, whereas passive interventions bring about the desired end 'by themselves'.2 Moreover, a continuum most likely exists ranging from extremely passive to extremely active interventions, with certain interventions lying somewhere in the middle (e.g., neurofeedback). Passive interventions may compromise an individual's autonomy and identity by hijacking one's ability to withdraw consent during treatment and by causing drastic, abrupt and/or concealed narrative identity changes. Whereas indirect interventions seem less likely to threaten our autonomy and identity due to the active involvement of the individual in question, direct neuromodulation has the potential to be more problematic in these respects. However, we argue that this does not necessarily need to be the case provided certain safeguards are put in place.

Although our paper focuses on moral enhancement and the means that may be used to morally enhance individuals, our arguments are also relevant with regard to the more general debate on biomedical means versus 'natural' means to treat and/or enhance individuals.

\footnotetext{
${ }^{2}$ We are aware of the fact that the term 'passive' in English typically refers to 'inactive' or 'inert', which would imply that passive interventions have no ability to change individuals, whereas active interventions do have the ability to change individuals. However, by 'passive' interventions we wish to refer to interventions that can bring about changes without any psychological involvement or effort on behalf of the individual, i.e., that make the individual a passive recipient [27]. Active interventions are then those interventions that need the psychological involvement or effort of the individual in question to come about. Passive/active thus refers to the involvement of the individual undergoing the intervention, and not to the potential of the intervention itself to bring about changes.

We use the terms direct/indirect similar to other authors in the bioenhancement debate [e.g., [27, 30, 43-45]. For example, Butblitz and Merkel [30] describe indirect interventions as interventions over which we have more control compared to direct interventions. Indirect interventions are mediated by "internal processes on the part of the addressee" [30: 69] whereas direct interventions are not. Hence, on this definition indirect aligns with active mental involvement on behalf of the individual, whereas direct aligns with no involvement on behalf of the individual and thus refers to changes that are passively brought about and can be described as "freedom-subverting" [44: 372]. To further clarify, passive interventions might be described as 'freedom incompatible' interventions, whereas active interventions might be described as 'freedom compatible' interventions.
}

\section{The Nature and Neurobiology of Moral Decision-Making and Behavior}

In our view, moral enhancement refers to interventions that aim to improve moral decision-making and behavior. In order to understand what this implies, and how this could be achieved, we first need to have an account of how moral decision-making and moral behavior 'work'.

Following Fischer and Ravizza's [7] account of moral responsibility, our capacity to be moral can be described as the ability to recognize non-moral and moral reasons and act upon these reasons. Their account draws upon the capacities or abilities humans may or may not (fully) possess in order to be considered morally responsible. Hence, being moral requires, at the very least, that an individual possesses these capacities or abilities to an average or close to average degree. Fischer and Ravizza [7] argue that the capacity for moral responsibility implies that an individual has the ability for reason-responsive behavior, comprising both a 'receptivity to reasons' and a 'reactivity to reasons'. Receptivity to reasons implies that the agent recognizes those reasons that are captured by "intuitively plausible conditions of rationality" [8: 97]. Reactivity to reasons involves the capacity to translate reasons into choices and subsequent behavior. According to Fischer and Ravizza [7], this means that an individual has to have the capacity or 'cognitive power' to recognize actual incentives to do otherwise (e.g., that addiction disrupts one's connectedness with family and loved ones), and has to display (some) reactivity to reasons in order to show that she has the 'executive power' to react to an actual incentive to do otherwise (e.g., if the individual can abstain from her drug of choice if the market price goes up). Fisher and Ravizza [7] further argue that the kind of reasonresponsiveness that is required for moral responsibility needs to be categorized as a responsiveness to a range of reasons, including (some, but not necessarily all) moral reasons. It is with this in mind that Fischer and Ravizza [7] argue that some psychopaths have diminished responsibility due to a lack of responsiveness to moral reasons.

Although Fischer and Ravizza pay little attention to the importance of affect with regard to the concept of reasons-responsiveness, "neuroscience research strongly indicates that emotional reactivity is a necessary 
process in the development of moral decisionmaking" [9: 53]. ${ }^{3}$

According to recent neuroimaging studies, and in line with developmental studies, moral reasoning draws upon a variety of neural networks, involving both affective, cognitive and motivational processes: "The regions recruited in moral cognition underlie specific states of emotions, along with cognitive and motivational processes, which emerge and interconnect over the course of development to produce adaptive social behavior" [9: $49,10,11]$. As we mature, increased 'communication' (structural and functional integration) between these networks takes place: "Thus, what develops is not only theory of mind but also the ability to integrate knowledge about others' thoughts with information about consequences and emotions in the context of moral judgment" [9: 53]. Moreover, recent neuroscience research has implicated the default mode network ${ }^{4}$ with regard to our capacity to be moral: "In our view, the regulation of moral behavior involves intricate (mainly frontal-temporal) brain systems supporting emotion processing and goal-directed reasoning, in which the default mode network may act as a large-scale connection contributing to integrate the emotional and cognitive processes in moral dilemma situations" [12: 918]. In sum, an individual's capacity to be moral (i.e., to recognize and respond to non-moral and moral reasons) appears to draw upon affective, cognitive and motivational processes that are neurologically and behaviorally intertwined.

\section{Defining Moral Enhancement}

Based upon the above discussion of moral decisionmaking and behavior, we tentatively suggest that moral enhancement would require the strengthening and/or instilling of 'moral capacities', that is: cognitive, affective and motivational capacities necessary for moral decision making and behavior. When discussing moral

\footnotetext{
${ }^{3}$ Based on the neurobiology and psychology of psychopathy, the first author previously argued that both reasons-receptivity and reasons-reactivity are to a greater or lesser degree impaired in (some) psychopaths and that these impairments draw upon dysfunctional affective and cognitive processing [46]

${ }^{4}$ The default mode brain network comprises a network of brain regions that are active when an individual is at rest, depicting an inward focus linked to introspection and self-referential thoughts instead of an outward focus on the world around us
}

enhancement, the debate thus far has focused mainly on 'isolated' aspects of human thought and behavior such as moral motives [13], (pro-social) emotions and moral dispositions [14-16], 'counter-moral emotions' [13], or moral rationality [4]. Emotions like fear can stimulate immoral behavior, but may just as well attenuate immoral behavior depending on the situation and the individual in question. Moral reasoning may lead to right moral decisions but without the motivation to be moral it will not be conducive to moral behavior. For it to be successful, moral enhancement will most likely require a focus on all the aspects of normal moral decisionmaking and behavior, and it will require interventions to be tailored to the individual in question. We cannot isolate 'moral reasoning' and think that it will be the gateway to moral enhancement, and we cannot isolate 'moral emotions' and think those will do the trick. In some individuals it might be enough to focus on either emotions, reasons or motives provided that the others aspects are functioning within the normal range, however, in many or even most others it will not. We have to be fully aware of the fact that the human mind is not made up of isolated capacities or traits. Although focusing on moral virtues $[17,18]$ could potentially provide a more holistic approach to moral enhancement, it may lack a sufficient focus on the motivational processes required for moral decision making and behavior. It may also prove extremely difficult to relate general traits such as specific 'virtues' (e.g., empathy) to neurobiological and/or genetic correlates [19].

According to Harris ethical expertise is not "being better at being good", but rather "being better at knowing the good and understanding what is likely to conduce to the good" [4:104]. We argue, however, that moral enhancement should not exclusively entail the instilment or the procurement of ethical expertise or insight, but should equally be conducive to doing the good. ${ }^{5}$ Similarly, moral enhancement should not merely increase the likelihood of doing right or good actions

\footnotetext{
${ }^{5}$ Although we agree with Harris that it is not necessarily so that "those with the insight, sympathy, empathy, understanding and knowledge to have formed clear ideas of what might conduce to the good" are better at "doing good in any of the ways in which this is possible" [4: 104], it cannot but raise the odds substantially that these individuals will do good. If not, this would entail that insight, sympathy, empathy, understanding and knowledge are not essential building blocks of what it means to be a good person. Of course circumstances can still tilt the individual towards wrongdoing, but under the right circumstances, the odds of behaving in a morally good way are raised substantially.
} 
and decrease the likelihood of doing wrong or bad actions without any corresponding change in moral reasoning or emotion. We do not consider this sufficient to speak of moral enhancement. Increased right or good actions need to be accompanied by an individual's understanding of what constitutes right and wrong actions, and thus by responsiveness to moral reasons, to consider certain interventions moral enhancements. Moreover, such a requirement enables the kind of moral enhancement that will likely be long-term and stable, i.e., able to resist all sorts of potential pitfalls of a kind of technology that exclusively targets behavioral outcomes and not the process of morality itself.

Although, for example, inducing a heightened capacity for fear in psychopaths may lead to an increase in the likelihood of these individuals doing right or good actions, it may not lead to an increase in their understanding of what constitutes right and wrong actions. Whereas interventions that increase fear in psychopaths may therefore be beneficial from a societal perspective and ethically defensible in their own right, such interventions do not amount to moral enhancements if they do not similarly induce an increased understanding of morality (i.e., responsiveness to moral reasons). Such interventions should be characterized as forms of behavior control, rather than as moral enhancement. In comparison, an individual with antisocial personality traits may possess (sufficient) understanding of what constitutes right and wrong, but at the same time may be unable to do good or right actions due to impairments in impulsivity and/or attention. Diminishing impulsivity and restoring or enhancing attention in these individuals may lead to an increase in the likelihood of these individuals doing right or good actions that are based on a sufficiently proper understanding of moral reasons. This may indeed be described as a moral enhancement. Similarly, increasing certain moral dispositions such as empathy in normal individuals, or increasing their reasoning skills, may lead to moral enhancement because normal individuals already posses some (more or less adequate) level of understanding of morality (i.e., responsiveness to moral reasons). Although certain outcome oriented interventions may achieve an increased likelihood of good actions (or decrease the likelihood of wrong ones), and may therefore be ethically defensible in themselves, we argue that moral enhancement should involve responsiveness to moral reasons. If such understanding is absent, the intervention should be understood as a form of behavior control.

\section{How to Attain Moral Enhancement?}

With regard to morally enhancing individuals that have 'normally' functioning morality ${ }^{6}$ - that is: average or close to average cognitive, affective and motivational capacities - the approach that is suggested by Harris will most likely be a good route to take: “... a combination of rationality and education, possibly assisted by various other forms of cognitive enhancement, in addition to courses or sources of education and logic" [4: 105]. This should likely be complemented with approaches that strengthen affective and motivational aspects of morality, as Harris implicitly acknowledges when he describes our traditional methods of moral development and enhancement, as "bringing children up to know the difference between right and wrong, to avoid inflicting pain or suffering on or doing harm to others; and instilling in them habits of respect for others" [4: 104]. Harris describes these as modes of respect that include "altruism, sensitivity and consideration and perhaps above all of being able to put ourselves in others' shoes so that we not only understand, but imaginatively experience, what it might be like to be on the receiving end of the conduct of others" [4: 104]. Although Harris is right that these traditional methods have been tried and tested, and have been shown to work in the average person, these methods will not be effective for everyone. For example, children with callous-unemotional traits or with severe ADHD, or other moderate to severe neurodevelopmental problems, may not be able to develop the necessary capacities even when vigorously stimulated (in traditional ways) to do so.

It is likely that traditional approaches will not suffice to effectively enhance morality in individuals that do not exhibit close to average or average cognitive, affective, motivational capacities. ${ }^{7}$ Enhancing morality cannot be achieved with a one-size-fits-all strategy and it will need

\footnotetext{
${ }^{6}$ How we can and should differentiate between normal and abnormal moral capacities or moral functioning, or how we can distinguish between average, or above- or below-average is a complex normative and empirical question. Answering these questions would require a separate paper. Yet another question is which means would be imaginable to increase moral capacities far above normal or average moral capacities, i.e., enhance morality beyond human norms [47]. We will not concerns ourselves with that latter question here.

${ }^{7}$ In cases where pathological deficiencies in moral capacities are present, we might speak of moral therapy or repair, rather than enhancement. Although the treatment-enhancement distinction has been much discussed and criticized, we believe that if understood as a merely descriptive distinction, it can help to clarify the discussion.
} 
to be tailored to the specific individual in question. In individuals for whom traditional means do not work, more direct forms of biological intervention - biomedical moral enhancement [13] or moral bioenhancement [16] have been suggested. Such biomedical interventions can range from vitamin and fish oil supplements, to medication and non-invasive magnetic brain stimulation, to more invasive and risky interventions like electrical deep brain stimulation. For example, a wide variety of medications, for example SSRIs and antipsychotics, can be successful in lowering impulsivity and aggression in adults and children [20,21] and neurofeedback is being investigated to manage risk factors for deviant, immoral behavior, such as ADHD [22] and substance use disorders [23, 24]. Also, more recently, small-scale investigational studies involving non-invasive neurostimulation such as tDCS and TMS seem to show some promise for the management of addictions (17 studies, medium effect size). Magnetic stimulation that targets the prefrontal cortex may increase cognitive control mechanisms, decrease craving levels, or both $[25,26]$. However, it must be kept in mind that right now, most of these interventions are in the early stages of research and development, and may or may not turn out to be effective approaches towards moral enhancement in the long run.

\section{Do Means Matter: Direct vs Indirect and Active vs Passive Moral Enhancement}

Even if the biomedical means for moral enhancement are still mainly hypothetical, we should consider whether the (further) development of such means is morally acceptable and desirable. Means to attain moral enhancement can be separated in indirect and direct interventions: indirect interventions aim to change thought patterns and behavior and thus rewire an individual's brain structure and functioning, whereas direct interventions aim to change brain structure and function and thereby an individual's thought patterns and behavior. Indirect (targeting the mind) and direct (targeting the brain) moral enhancement are different ways of achieving the same end, i.e., moral betterment. Most 'traditional' means to attain moral enhancement, such as education, are indirect in this sense, while biomedical moral enhancements tend to be direct. It is important to keep in mind, however, that changing either brain or mind inevitably involves changing both. Indirect interventions such as talk therapy, as well as direct interventions such as DBS, target the brain's capacity for reorganization to exert their effects, and one could argue that the results are, in the end, the same. Talk therapy uses our brain's capacity for reorganization by directly influencing mental states and thus indirectly the brain states underlying our mental states, whereas DBS uses our brain's capacity for reorganization by directly influencing brain states and thus indirectly the mental states that result from this direct 'rewiring' of the brain. Neurofeedback can be seen as an intermediary. Neurofeedback targets an individual's mental states while linking these mental states to specific brain activation patterns. ${ }^{8}$ However, the brain activation patterns are changed in a more direct way as compared to talk therapy - because the individual chooses to reiterate certain thoughts/mental states in order to achieve the desired brain activation patterns. So neurofeedback could be seen as targeting both mental states and brain states in a direct way, or at least more direct/less indirect as compared to talk therapy.

Intuitively it seems that indirect means are more in tune with the nature of moral decision-making and behavior ${ }^{9}$ and the importance that is typically placed on freedom within the realm of moral decisions and acts. ${ }^{10}$ Although both direct and indirect moral

\footnotetext{
${ }^{8}$ During neurofeedback training, feedback of neural metabolic activity is brought to the attention of the participant by the use of an interactive graphic display with the aim of conditioning area specific brain processes. Several fMRI neurofeedback studies have demonstrated that humans can learn to self-regulate localized brain regions, including emotional brain regions, based on a combination of contingent feedback and mental strategies [48].

${ }^{9}$ As outlined above in section 3-5: The interconnectedness of emotions, reasons and motives in normal moral decision-making and behavior, both from a neurobiological and experiential perspective.

${ }^{10}$ See the discussion on 'freedom to fall' within the moral enhancement debate [4, 13, 19, 43, 49-51; and others]. According to Persson \& Savulescu [3], Harris fears that moral bioenhancement will "make the freedom to do immoral things impossible, rather than simply make the doing of them wrong and giving us moral, legal and prudential reasons to refrain" [4: 105]. Which basically entails that he fears that we will no longer act for reasons, but will become "mindless robots" [3: 128]. One may argue that moral enhancement, to be successful, should render an individual's reasons and/or motives for doing good more salient, and make these play a (more) salient role in one's decision-making processes, but should not make individuals "mindless robots". Doing good should still remain an option, a behavior of choice, among the many options that individuals may have. Moral enhancement should therefore not curtail our 'freedom to behave immoral', but if successful, it will make immoral behavior less likely by, for example, making it easier to resist certain counter-moral incentives. It should provide a way to make "the unacceptable unpalatable", not undoable [52: 170].
} 
enhancement may be effective, moral intuition may favor more traditional, indirect means, over direct biomedical ones to achieve moral betterment. Is this intuition sustainable? Does it matter morally whether mental states and/or brain states are targeted directly or indirectly? An obvious reply is that it matters with regard to potential risks and side effects, which may be bigger with direct brain interventions - but does it matter in any other morally relevant way?

We believe that the distinction between direct and indirect interventions tracks an underlying distinction between interventions that require active involvement and effort of the person in question, and those that allow for the subject to remain a 'passive recipient' [27, 28]. This is a morally relevant distinction, since - as we will argue below - passive interventions have a greater potential to compromise autonomy and identity. Hence, we argue that the distinction between direct and indirect is morally relevant insofar as it relates to the distinction between passive and active.

When we travel alongside the continuum from indirect to direct interventions, we are also travelling alongside interventions that (potentially) leave less and less room for active psychological and behavioral involvement in the changes that are induced, and less and less room for rational reflection and deliberation upon those changes. The more direct an intervention becomes, the more passive the individual that is receiving it will be with respect to the changes that are induced. For example, successful DBS for tremor in Parkinson's disease does not require any effort on behalf of the patient to reach its goal. Of course, it requires active involvement and effort to undergo surgery and battery replacements, to deal with any side effects should these occur, and to adjust to the new situation. However, it does not require any effort on behalf of the patient to stop the tremor - the device and the electrical stimulation do this 'all by themselves'. A similar 'passive receiver' set-up is involved in TMS or tDCS. Neurofeedback, which is less passive compared to deep brain stimulation or noninvasive magnetic brain stimulation, requires the execution of a specific computer task tailored to the needs of the individual in order for the training to work. Cognitive behavioral therapy, which is an active process by nature, depends to a large extent on the mental effort of the individual during therapy, as well as in consciously applying therapist suggested mental strategies on a day to day basis. Moral education and learning can be described as an active process of trial and error involving personal experience and psychological effort to exert its effects.

Passive interventions such as DBS and TMS or tDCS do not rely on the active involvement of the receiver to achieve their goal, and therefore carry a substantial risk of bypassing conscious reflection, continuous rational deliberation and autonomous choice. This may compromise both autonomy and identity, as we will discuss in the next sections.

\section{Limiting Continued Rational Deliberation and Autonomous Choice}

Being autonomous means leading one's life in accordance with one's own choices, that is, choices that are based on the values and goals we endorse after deliberation. Part of being an autonomous individual involves having the freedom and ability to withdraw from interventions or treatments that we no longer rationally endorse. This means that after giving one's informed consent, it remains possible to withdraw from the intervention or treatment at any given time. For example, an individual with advance-stage cancer may rationally opt to undergo aggressive chemo therapy even though the chances of being cured are extremely slim, but that same individual after consenting to treatment may also rationally opt to withdraw from treatment even if she thus faces death. Depending on whether active or passive means of moral enhancement are used, an individual's freedom to withdraw from the intervention may be more threatened or compromised. Passive enhancement may even be applied without consent from the subject, since it does not depend on active participation or involvement for its success.

An individual undergoing cognitive behavioral therapy - an active intervention - for her anger management and impulse control problems may feel that the ways in which she is changing is either worthwhile, because it helps her to stay out of trouble and lead a more regular life, or she may feel that it threatens what she finds important in life, like being spontaneous or living on the edge. Because cognitive behavioral therapy takes a lot of active participation of the individual, and because it is a gradual process for which the success depends to a large part on the active participation and effort of the individual, ample room is left for the individual to rationally reflect upon the changes that are brought about as the intervention continues and to withdraw from the intervention if one cannot identify with these 
changes, or to reject certain changes and endorse others. By contrast, when directly altering an individual's brain functioning, subsequent changes to ones identity cannot be deliberated on in the same gradual manner and cannot be selectively endorsed or rejected. Direct moral enhancement, more so than indirect moral enhancement like education, therefore carries the risk or even threat of "coercive normalization" [29: 672] or coercive change, especially if given to children by their parents or offered to criminals as an alternative sanction. Recently Bublitz and Merkel [30], in concordance with our approach, argued that individuals have a right to mental selfdetermination and that there are limits to the ways in which we may legitimately change mental states in others. Respect for 'mental integrity' is voiced in Art. 3 of the EU Charter of Fundamental Rights and falls under the scope of Art. 8 of the European Convention of Human Rights. We agree with Bublitz and Merkel [30] that respect for persons entails respect for an individual's first-person perspective and entails prohibitions on direct interventions without consent. Nevertheless - and we agree with this point as well - they claim that, within certain limits, direct interventions can be justified if a informed consent is given.

\section{Threats to Identity}

Interventions aimed at moral enhancement have the potential to threaten a person's narrative identity [31, 32]. According to Schechtman [33], narrative identity reflects the characteristics that constitute a person's identity. Put simply, the characterization question asks "which actions, experiences, beliefs, values, desires, character traits, and so on ... are to be attributed to a given person" [33: 73]. According to DeGrazia narrative identity involves "what is most central and salient in a given person's self-conception" [31: 266]. Narrative identity is thus in line with recent notions of personality in psychology and psychiatry, in which personality is defined as "a dynamic and organized set of characteristics in a person that uniquely influences his or her cognitions, motivations, and behaviors in various situations" [34: 4], rather than a fixed set of psychological traits that define the true self $[35,36]$. Central to a narrative view of identity is the fact that identity is understood in the "dynamics of psychological change" [36:137], meaning that an individual's beliefs, desires, personality traits and so on may change over time. However, it is important for the continuity of narrative identity that such changes are or can be incorporated in one's life story in a coherent way, without compromising one's sense of self.

Identity changes can either be in tune with one's narrative self-concept or be experienced as disruptive of one's narrative. If disruptive, it means that the changes do not align (well) with the individual's actions, experiences, beliefs, values, desires and character traits that are constitutive of her identity.

\section{Radical and/or Abrupt Narrative Identity Changes}

While interventions aimed at moral enhancement will inevitably influence one's narrative identity - since it is their purpose to change one into a more moral person they may do so in different ways. Mild or moderate identity changes due to indirect (e.g., therapy, exercise) or direct interventions (e.g., SSRIs, non-invasive magnetic brain stimulation, DBS) are not necessarily problematic. Mild and moderate identity changes are a normal part of the way in which life unfolds and may result from a variety of life-changing experiences or circumstances. For example, becoming a parent may change an individual from being somewhat irresponsible to becoming responsible. The loss of a loved one may change someone from being optimistic and cheerful, to being overly cautious, sad and depressed. However, direct, passive interventions like DBS may induce such radical and/or abrupt changes, with little or no link to an individual's narrative life story, that the continuity of one's narrative identity may be threatened.

Schechtman [36] has discussed whether radical and/ or abrupt psychological changes due to DBS - a passive intervention - interfere with our identity in an ethically objectionable way. DBS patients express post-operative difficulties adjusting to psychological changes and changes in functional status, as well as to adopting a new self-image [37]. Also, some patients report difficulty to accept the presence of an electronic device in their brain, as if they were now a robot or electronic puppet, alienated from their own narrative $[36,38]$. Some individuals may experience such acute and dramatic changes in their psychological make-up that it frightens them, and leaves them feeling alienated and without a sense of control and/or agency. Schechtman gives an example of a depressed person: "The psychological changes brought about are so profound and occur so quickly that they can seem to break off one narrative - the story of a depressed person - and start a new one - that of a happy 
person" [36: 137]. One could image, however, similar difficulties if a former psychopath was suddenly turned into a empathic, warm person; if an aggressive and short-tempered man suddenly turned into a soft and easy-going one; or if a goal-seeking, dynamic women turned into a disinterested individual that completely lost her drive and vitality.

Although radical and/or abrupt changes may indeed be disrupting to one's identity, this need not necessarily be the case, and it need not render the intervention unethical. An individual may experience, or regain, a continuity of her narrative identity, even despite radical change, if such changes are properly understood, anticipated and supported. If the individual, through pre- and post-intervention guidance and counselling, can foresee and properly understand the potential for psychological changes, these changes can be incorporated in one's narrative self-concept in a coherent manner and may be experienced as self-directed and even self-expressive. We agree with Schechtman that psychological changes, even dramatic ones, can indeed be coherently incorporated in one's life story if such safeguards are put in place. This means that proper informed consent procedures and pre- and post-intervention-counselling are essential requirements for an ethical application of passive forms of moral enhancement. Subjects should be enabled to actively incorporate the passively induced changes in their narrative identity.

\section{'Concealed' Narrative Identity Changes}

There is another way, however, in which one's narrative identity may be disrupted by direct interventions like DBS, that we consider to be more problematic from an ethical perspective. DBS may result in narrative identity changes that go (partially) unnoticed (e.g., very mild or subtle changes that may have more serious long-term effects on personal relations) or are denied (e.g., instances where the magnitude of the changes or the consequences thereof are underestimated) by the individual in question, although they are noticed by the family, loved ones or co-workers. For example, Leentjes and colleagues [39] describe a case study of an individual with Parkinson's disease who became euphoric and disinhibited after DBS surgery. The 62-year old man entered a relationship with a married women and started spending huge amounts of his savings on clothing and partying. His disinbition and megalomania gradually worsened into a manic disorder. He bought several houses by taking up several mortgages. He bought a few new cars, got into car accidents and temporarily lost his driver's license. While the stimulation was turned on the man displayed impaired judgment and a total denial of his changed personality and psychiatric symptoms. When the stimulation was turned off his motor symptoms returned, but he did admit to having psychiatric symptoms and impaired judgment while the stimulation was turned on. In several individuals receiving DBS treatment, not readily apparent, mild forms of irritability, impatience and distractions on behalf of the patient, put strain on existing relationships, aggravate preexisting marital problems and frequently lead to familial conflicts and adjustment problems at work [38].

One important element regarding narrative identity is that it can be assessed both from a first-person and thirdperson perspective. One such example of the thirdperson perspective is "the startled "Who are you?" we can imagine coming from Ted Bundy's fiancée when she discovers that the personable law student with whom she meant to spend her life is a serial killer" [33: 75], but there are of course much less extreme cases such as when finding out that your partner, who you thought was committed, is having an affair. In contrast, the first person-perspective draws upon an individual's own assessment of the narrative identity changes that she experience throughout life. To be sufficiently aware of one's narrative identity, a narrator must be able to coherently 'explain' or communicate the narrative unfolding of her life story.

Schechtman [33] argues that individuals may experience 'self-blindness' at times and describes this as cases in which an individual's explicit self-narrative diverges from her implicit self-narrative. This implicit selfnarrative can be understood as "the psychological organization from which experience and actions are actually flowing", reflecting "a dynamic set of organizing principles, a basic orientation through which, with or without conscious awareness, an individual understands himself and his world" [33: 115-116].

Direct interventions aimed at moral enhancement may involve psychological changes in this set of organizing principles that go (partially) unnoticed by the individual in question and thus are perceived as part of her pre-enhanced identity, or may involve changes that are underestimated or even denied. Although direct interventions like DBS may evoke feelings of alienation in some 
patients, it is equally possible that they result in the unreflective self-incorporation or underestimation of certain new traits. This unreflective selfincorporation or underestimation may be due to the directness of the technique ${ }^{11}$ which leaves the person a passive recipient of these changes, rather than an active agent. This might lead individuals to unreflectively accept or even welcome certain traits that would not be similarly endorsed by their pre-interventional/pre-enhanced self. Because these changes occur (partially) unnoticed, one's capacity to rationally deliberate on and reflectively endorse or resist these changes is removed. It may therefore result in a dissociation between one's implicit narrative self and one's explicit narrative self, that means: in a situation of self-blindness. While such a dissociation is clearly problematic as it has the potential to disrupt one's personal and professional relations, it is also problematic from an intrinsic perspective because self-blindness, in this sense, is a form of inauthenticity that threatens the autonomy of the self.

In line with DeGrazia's theory of personal narrative identity [31], we claim that in order for identity changes to result in an autonomous self, in an authentic narrative identity, an individual must be able to reflectively and deliberatively approve or disapprove of the changes that occur during her life. Following DeGrazia, whether new traits, preferences or values that a person acquires become a true part of the person's explicit and autonomous narrative identity, depends on two things: whether the person identifies with his new traits or desires; and whether she identifies with their genesis, i.e., the way they came about [28]. This requires, first of all, that he individual has to be aware of these changes. Changes that go unnoticed or are denied, like concealed narrative identity changes, thus pose a threat to one's autonomy and identity.

\footnotetext{
${ }^{11}$ Because direct neuromodulation affects the entire brain (by directly stimulating part of a network in the brain that interacts with other areas and networks in the brain) subsequent psychological and personality changes may either go unnoticed by the individual in question and leave the individual without any means to reflect upon, or rationally endorse, her changed identity, or may lead one to unreflectively accept or welcome certain traits. If we take into account the way our brain works it is not unlikely that directly changing an individual's moral dispositions (e.g., empathy, sense of justice, sense of fairness) will affect one's entire belief system, i.e., in such a way that the individual in question does not necessarily experience a discontinuity as such.
}

In order to minimize this threat of concealed changes to ones autonomy and identity, we propose a number of measures. First, the individual should be prospectively informed about the possibility and nature of potential narrative identity changes, and the fact that some of these changes may go unnoticed by herself but will be noticeable to others. This should be part of the informed consent procedure for direct interventions.

Second, persons undergoing a direct intervention like DBS should be maximally enabled to reflect on these changes and to choose to endorse or reject them; this should be part of the postintervention counseling. For concealed changes, this means they should be brought to the person's attention and discussed with her as much as possible, in order to enable her to reflect on them and integrate them in her personal narrative. Not all concealed changes need to remain concealed. Selfblindness need not be permanent and unintended changes in the self can become an authentic part of one's narrative identity over time if one reflectively endorses these changes. This implies that direct, passive means for moral enhancement must be accompanied by supportive interventions that actively involve the enhanced person herself.

The primary responsibility for ensuring informed consent as well as for providing adequate pre- and post-intervention counselling would lie with the treatment team (e.g., expert medical team or licensed psychologist). As with any medical intervention - and we believe an invasive intervention in the brain should be considered as such - the treating physician or psychologist is responsible for ensuring the quality of care. ${ }^{12}$ Treatments consisting of direct interventions in the brain should be considered as a 'global treatment'; it does not only focus on the brain but on the whole person in interaction with his environment [40]. The treatment consist not only of the actual operation, but includes the fine-tuning of the electric parameters as well as the

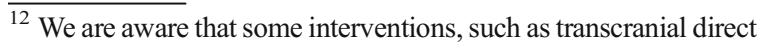
current stimulation (tDCS), can currently be applied on a do-ityourself basis, hence without a responsible medical practitioner in charge. For reasons of patient safety and well-being, we would recommend that such interventions are regulated by legal measures for product safety and personal use (e.g., licenses for personal use involving training sessions with skilled experts) in the short-term while undergoing regulation by the Medical Devices Directive (MDD) in the long term [53].
} 
necessary psycho-social support. ${ }^{13}$ With regard to the question of financial responsibility, we believe this would depend on the context. Different countries have different insurance regimes for covering medical costs, people might choose to enhance themselves at their own expenses or, if moral enhancement would be used in the context of a criminal justice system, costs might be covered by the budget of the Justice Department or Health Department.

\section{Conclusion}

If we as a society and as individuals want to contribute to a morally better world in which public and personal well-being are valued and pursued, moral enhancement is an important option to consider. Moral enhancement entails, we have argued, strengthening or instilling cognitive, affective and motivational capacities necessary for moral decision making and behavior, in a way that makes - or leaves - people responsive to moral reasons. In individuals with normal capacities for moral decision-making and behavior, moral enhancement can likely be achieved through traditional, indirect means such as moral education and social learning. However, in individuals with impairments in moral decisionmaking and behavior or counter-moral personality traits, such means might not suffice to achieve moral betterment and biomedical, direct means come into focus as a potential - although presently largely hypothetical solution. Moral intuition seems to favor indirect means over direct means as direct means often raise worries and uncertainties considering their potential for harm

\footnotetext{
${ }^{13}$ An important question that links to these issues is whether enhanced individuals themselves should take responsibility for unwanted adverse behavioral effects. This question is not unique to the moral enhancement debate and similar problems have arising within various other treatment settings (e.g., medications for psychiatric disorders, DBS for movement disorders, psychosurgery). For example, following a cingulotomy for treatmentrefractory obsessive compulsive behavior, patients may exhibit clinical disinhibition. Cases are known of such patients committing sexual offences post-operatively. Can we hold such individuals (fully) responsible for their deviant behavior? Similarly, are technologically enhanced individuals responsible for any unexpected adverse effects that may arise? For example, think of the use of moral bioenhancement within criminal justice settings, should we hold the criminal justice system or the offender responsible for adverse, unwanted behavioral effects, or both? [see, e.g., $45,54,55]$
}

due to side effects, risks and abuse, as well as intrinsic doubts concerning authenticity and autonomy.

Is it the case that indirect means are morally preferable to direct means of moral enhancement and can we indeed pinpoint relevant intrinsic, moral differences between both? We argue that the distinction between direct and indirect means is indeed morally relevant, but only insofar as it tracks an underlying distinction between active and passive interventions. Although passive interventions can be ethical provided specific safeguards are put in place, these interventions exhibit a greater potential to compromise autonomy and disrupt identity. First, direct, passive interventions limit an individual's capacity for continued rational deliberation and autonomous choice. When directly altering an individual's brain functioning, psychological changes cannot be deliberated on in the same gradual manner and cannot be similarly selectively endorsed or rejected as is the case in indirect, active interventions. The gradual nature of the enhancement process in active interventions does, in general, allow for rational deliberation and autonomous choice as the intervention continues, and one can easily put a stop to further changes by discontinuing the intervention. Second, direct, passive interventions may induce such radical and/or abrupt psychological changes, with little or no link to an individual's narrative life story, that the continuity of one's narrative identity is threatened. However, such psychological changes, even radical ones, can be coherently incorporated in one's life story provided that proper informed consent procedures and pre- and post-intervention-counseling are put in place. Third, the possibility of concealed narrative identity changes, changes that, to a lesser or greater extent, go unnoticed or are denied by the individual undergoing the treatment may result in a situation of self-blindness. Self-blindness can be construed as a form of inauthenticity that threatens the autonomy of the self because one obviously cannot reflectively and deliberatively approve or disapprove of such implicit, unrecognized psychological changes. Prospectively informing individuals about the possibility and nature of such changes and post-intervention counseling can aid individuals in overcoming instances of psychological self-blindness and in learning to cope with disrupted social-emotional relations.

In sum, direct biomedical moral enhancements can be ethically acceptable if such interventions are voluntary, and if, as outlined above, specific conditions to safeguard autonomy and identity are met. This means 
that passive interventions ought to be accompanied by supportive interventions that actively involve the subject of the intervention. In general, passive interventions aimed at moral enhancement should be treated especially cautious compared to active interventions both with respect to their overall moral acceptability and with respect to their potential use within the criminal justice and public health domain.

Acknowledgments The research for this paper was funded by the Netherlands Organization for Scientific Research (NWO) and the Scientific Research Foundation Flanders (FWO) as part of the project Our brain as capital.

\section{References}

1. Buchanan, A. 2011. Beyond humanity?. Oxford University Press.

2. Raus, K., F. Focquaert, M. Schermer, J. Specker, and S. Sterckx. 2014. On defining moral enhancement: a clarificatory taxonomy. Neuroethics. doi:10.1007/s12152-014-9205-4.

3. Persson, I., and J. Savulescu. 2013. Getting moral enhancement right: the desirability of moral bioenhancement. Bioethics 27(3): 124-131.

4. Harris, J. 2011. Moral enhancement and freedom. Bioethics 25(2): 102-111.

5. Levy, N. 2007. Neuroethics. Challenges for the 21st century. Cambridge University Press. [Check Johan B.'s office].

6. Greely, H. 2008. Neuroscience and criminal justice: not responsibility but treatment. University of Kansas Law Review 56(5): 1103-1138.

7. Fischer, J.M., and M. Ravizza. 1998. Responsibility and control. A theory of moral responsibility. Cambridge University Press.

8. McKenna, M.S. 2000. Assessing reasons-responsive compatibilism. International Journal of Philosophical Studies 8: 89-124.

9. Decety, J., and N.H. Howard. 2013. The role of affect in the neurodevelopment of morality. Child Development Perspectives 7(1): 49-54.

10. Pascual, L., P. Rodrigues, and D. Gallardo-Pujol. 2013. How does morality work in the brain? a functional and structural perspective of moral behaviour. Frontiers in Integrative Neuroscience 7(65): 1-8.

11. Young, L., and J. Dungan. 2012. Where in the brain is morality? everywhere and maybe nowhere. Social Neuroscience 7(1): 1-10.

12. Pujol, J., I. Batalla, O. Contreras-Rodriguez, B.J. Harrison, V. Pera, R. Hernandez-Ribas, and N. Cardoner. 2012. Breakdown in the brain network subserving moral judgment in criminal psychopathy. SCAN 7: 917-923.

13. Douglas, T. 2013. Moral enhancement via direct emotion modulation: a reply to John Harris. Bioethics 27(3): 160-168.

14. Chan, S., and J. Harris. 2011. Moral enhancement and prosocial behaviour. Journal of Medical Ethics 37(3): 130-131.
15. Crockett, M.J. 2014. Moral bioenhancement: a neuroscientific perspective. Journal of Medical Ethics 40(6): 370-371.

16. Persson, I., and J. Savulescu. 2011. The turn for ultimate harm: a reply to Fenton. Journal of Medical Ethics 37(7): 441-444.

17. Walker, M. 2009. Enhancing genetic virtue: a project for twenty-first century humanity? Politics and the Life Sciences 28(2): 27-47.

18. Jotterand, F. 2011. "Virtue engineering" and moral agency: will post-humans still need the virtues? AJOB Neuroscience 2(4): 3-9.

19. Bronstein, J. 2010. Objecting to the genetic virtue program. Politics and the Life Sciences 29(1): 85-87.

20. De Deyn, P.P., and J. Buitelaar. 2006. Risperidone in the management of agitation and aggression associated with psychiatric disorders. European Psychiatry 21: 21-28.

21. Pappadopulos, E., S. Woolston, A. Chait, M. Perkins, D.F. Connor, and P.S. Jensen. 2006. Pharmacotherapy of aggression in children and adolescents: efficacy and effect size. Journal of the Canadian Academy of Child and Adolescent Psychiatry 15(1): 27-39.

22. Gevensleben, H., B. Holl, B. Albrecht, D. Schlamp, O. Kratz, P. Studer, and H. Heinrich. 2009. Distinct EEG effects related to neurofeedback training in children with ADHD: a randomized controlled trial. International Journal of Psychophysiology 74(2): 149-157.

23. Arani, F.D., R. Rostami, and M. Nostratabadi. 2010. Effectiveness of neurofeedback training as a treatment for opioid-dependent patients. Clinical EEG and Neuroscience 41(3): 170-177.

24. Sokhadze, T.M., R.L. Cannon, and D.L. Trudeau. 2008. EEG biofeedback as a treatment for substance use disorders: review, rating of efficacy, and recommendations for further research. Applied Psychophysiology and Biofeedback 33: 1-28.

25. Conti, C.L., and E.M. Nakamura-Palacios. 2014. Bilateral transcranial direct current stimulation over dorsolateral prefrontal cortex changes the drug-cued reactivity in the anterior cingulate cortex of crack-cocaine addicts. Brain Stimulation 7: $130-132$

26. Jansen, J.M., J.G. Daams, M.W.J. Koeter, D.J. Veltman, W. van den Brink, and A.E. Goudriaan. 2013. Effects of noninvasive neurostimulation on craving: a meta-analysis. Neuroscience and Biobehavioral Reviews 37: 2472-2480.

27. Raus, K., F. Focquaert, M. Schermer, J. Specker, and S. Sterckx. 2014. On defining moral enhancement: a clarificatory taxonomy. Neuroethics 7: 263-273.

28. Schermer, M. 2015. Reducing, restoring or enhancing autonomy with neuromodulation techniques. In Free will and the brain: neuroscientific, philosophical and legal perspectives, ed. W. Glannon. Cambridge University Press.

29. Bradshaw, H.G., and R. Ter Meulen. 2010. A transhumanist fault line around disability: morphological freedom and the obligation to enhance. Journal of Medicine and Philosophy 35: 670-684.

30. Bublitz, J.C., and R. Merkel. 2014. Crimes against minds: on mental manipulations, harms, and a human right to mental self-determination. Criminal Law and Philosophy 8: 51-77.

31. DeGrazia, D. 2005. Enhancement technologies and human identity. Journal of Medicine and Philosophy 30(3): 261-283.

32. Schermer, M. 2009. Changes in the self: the need for conceptual next to empirical research. $A J O B$ 5: 45-47. 
33. Schechtman, M. 1996. The constitution of selves. New York: Cornell University Press.

34. Synofzik, M., and T.E. Schlaepfer. 2008. Stimulating personality: ethical criteria for deep brain stimulation in psychiatric patients and for enhancement purposes. Biotechnology Journal 3: 1511-1520.

35. Focquaert, F., and D. De Ridder. 2009. Direct intervention in the brain: questions concerning personal identity. Journal of Ethics in Mental Health 4: 1-7.

36. Schechtman, M. 2010. Philosophical reflections on narrative and deep brain stimulation. The Journal of Clinical Ethics 21(2): 133-139.

37. Gisquet, E. 2008. Cerebral implants and Parkinson's disease: a unique form of biographical disruption? Social Science \& Medicine 67: 1847-1851.

38. Schüpbach, M., M. Gargiulo, M.L. Welter, L. Mallet, C. Béhar, J.L. Houeto, and Y. Agid. 2006. Neurosurgery in Parkinson disease. A distressed mind in a repaired body? Neurology 66: 1811-1816.

39. Leentjes, A.F.G., V. Visser-Vandewalle, T. Temel, and F.R.J. Verhey. 2004. Manipulation of mental competence: an ethical problem in a case of electrical stimulation of the subthalamic nucleus for severe Parkinson's disease. Nederlands Tijdschrift Voor Geneeskunde 148: 1394-1398.

40. De Haan, S., E. Rietveld, and D. Denys. 2014. Stimulating good practice: what an EEC approach could actually mean for DBS practice. AJOB Neuroscience 5: 46-48.

41. Bërgstrom, L.S., and N. Lynoë. 2008. Enhancing concentration, mood and memories in healthy individuals: an empirical study of attitudes among general practitioners and the general population. Scandinavian Journal of Public Health 36: 532537.

42. Riis, J., J.P. Simmons, and G.P. Goodwin. 2008. Preferences for enhancement pharmaceuticals: the reluctance to enhance fundamental traits. Journal of Consumer Research 35(3): 495-508.

43. DeGrazia, D. 2014. Moral enhancement, freedom, and what we (should) value in moral behaviour. Journal of Medical Ethics 40(6): 361-368.
44. Harris, J. 2014. Taking liberties with free fall. Journal of Medical Ethics 40(6): 371-374.

45. Vincent, N.A. 2013. Restoring responsibility: promoting justice, therapy and reform through direct brain interventions. Criminal Law and Philosophy 8: 21-42.

46. Focquaert, F., Glenn, A., and A. Raine. 2015. Psychopathy and free will. In Free will and the brain: neuroscientific, philosophical and legal perspectives, ed. W. Glannon. Cambridge University Press.

47. Agar, N. 2010. Enhancing genetic virtue? Politics and the Life Sciences 29(1): 73-75.

48. Renaud, P., Joyal, C., Stoleru, S., Goyette, M., Weiskopf, M., and N. Birbaumer. 2011. Real-time functional magnetic imaging-brain-computer interface and virtual reality: promising tools for the treatment of pedophilia. In Progress in Brain Research, eds. Andrea M. Green, C. Elaine Chapman, John F. Kalaska and Franco Lepore, 263-272. Elsevier.

49. Douglas, T. 2008. Moral enhancement. Journal of Applied Philosophy 25(3): 228-245.

50. Harris, J. 2013. Moral progress and moral enhancement. Bioethics 27(5): 285-290.

51. Savulescu, J., and I. Persson. 2012. Moral enhancement, freedom and the God machine. The Monist 95(3): 399421.

52. Harris, J. 2013. 'Ethics is for bad guys!' putting the 'moral' into moral enhancement. Bioethics 27(3): 169-173.

53. De Ridder, D., S. Vanneste, and F. Focquaert. 2014. Outstanding questions concerning the regulation of cognitive enhancement devices. Journal of the Law and Biosciences 1: 316-321.

54. Klaming, L., and P. Haselager. 2013. Did my brain implant make me do it? questions raised by DBS regarding psychological continuity, responsibility for action and mental competence. Neuroethics 6: 527-539.

55. Vincent, N.A. 2013. Enhancing responsibility. In Neuroscience and legal responsibility, ed. N. Vincent, 305333. Oxford University Press. 